UNIVERSIDADE ESTADUAL DE FEIRA DE SANTANA

Autorizada pelo Decreto Federal $\mathrm{n}^{\circ} 77.496$ de 27/04/76
Recredenciamento pelo Decreto ${ }^{\circ} 17.228$ de 25/11/2016

PPPG PRÓ-REITORIA DE PESQUISA E PÓS-GRADUAÇÃo

COORDENAÇÃO DE INICIAÇÃO CIENTÍFICA

XXIV SEMINÁRIO DE INICIAÇÃO CIENTÍFICA DA UEFS

SEMANA NACIONAL DE CIENTÍFICA E TECNOLÓGICA - 2020

\title{
GEOPROCESSAMENTO, CADASTRO IMOBILIÁRIO E CRESCIMENTO DO BAIRRO MUCHILA: METODOLOGIA PARA GERIR A CIDADE DE FEIRA DE SANTANA.
}

\section{$\underline{\text { Adriana Assis da Silva'; Janio Santos }}{ }^{2}$;}

\author{
1. Bolsista PIBITI/CNPq, Graduanda em Bacharelado em Geografia, Universidade Estadual de Feira de Santana, e- \\ mail: drika_assis11@hotmail.com
}

2. Jânio Laurentino de Jesus Santos, Doutor em Geografia, Departamento de Ciências Humanas e Filosofia, Universidade Estadual de Feira de Santana, e-mail: Janiosantos@yahoo.com.br

PALAVRAS-CHAVE: Geoprocessamento, Cadastro Imobiliário, Muchila

\section{INTRODUÇÃO}

Em Feira de Santana, a expansão urbana vem sendo destaque periodicamente, sobretudo, devido ao crescimento territorial da cidade, por conta do cruzamento de três grandes rodovias federais (BR 324, BR 116 E BR 101) e cinco estaduais (BA 052, BA 084, BA 502, BA 503 E BA 504), que intensificou o interesse dos investidores de atividades terciárias, pois o tráfico de viajantes é considerado muito intenso e contribui no aumento das estatísticas financeiras.

Diante dos aspectos de crescimento em Feira de Santana, surgiram bairros que caracterizam uma dinâmica no crescimento da cidade, é o caso do bairro Muchila, localizado no perímetro urbano, composto pelos Conjuntos Muchila I, Muchila II e Feira $\mathrm{X}$, os quais possuem 22.816 habitantes e é classificado como o terceiro mais populoso, segundo o IBGE (2010).

O objetivo deste resumo consiste em elaborar um modelo de cadastro imobiliário que seja adequado ao acompanhamento da expansão urbana e do registro do uso do solo, com base na investigação do Bairro Muchila. O trabalho viabilizou a possibilidade de ações junto à Secretaria da Fazenda do Município para melhorias no acompanhamento do crescimento da cidade e auxilia nas análises de transformação das áreas em expansão em Feira de Santana.

\section{MATERIAL E MÉTODOS}

Para compreender o crescimento urbano nessa área, foi necessário a busca por referências bibliográficas que ajudam na compreensão sobre a organização espacial e as relações que o setor terciário mantem com o bairro, face a implantação de lojas, mercados, serviços e conveniências. Os conceitos de desenvolvimento urbano e periferia urbana são os principais que foram trabalhados, além dos debates sobre SIG e Geoprocessamento.

$\mathrm{Na}$ pesquisa de campo, foram aplicados 50 questionários, 25 aos moradores e 25 aos proprietários de comércio local do bairro, para verificar as características deles e as mudanças ocorridas, 3 entrevistas com poder público 2 com moradores antigos. Por fim os dados obtidos serviram para construção de mapas no software Qgis, com mapas de localização e uso e ocupação do solo. 


\section{CADASTRO IMOBILIÁRIO E DESENVOLVIMENTO URBANO.}

Para Souza (1997), desenvolvimento urbano ocorre de maneira processual e se reinventa a cada avanço técnico-científico de forma particular e articulada e a cada singularidade construída socialmente e economicamente. Ele está impregnado de juízo de valor e se presume a mudança e transformação, ao passo que forja sentido positivo e/ou desejável, sendo atrelado a conhecimentos históricos, étnicos e político-filosófico.

O geoprocessamento é a disciplina do conhecimento e o Sistema de Informações Geográficas (SIG) é a ferramenta computacional para sua utilização. O geoprocessamento pode ser utilizado nos mais variados ramos de atuação de uma prefeitura, sendo importante aliado no levantamento de dados, visualização de problemas, tomada de decisão, projetos, planejamento, execução e monitoramento de ações. Um exemplo da possibilidade da utilização dessa geotecnologia é a análise, com base na relação direta entre propriedade fundiária, unidade domiciliar e tipo de uso, para traçar ações conjuntas para melhoria dessas características. (CODOVEZ, 2002).

O cadastro territorial multifinalitário ou cadastro imobiliário, segundo Loch (2005 apud ARGENTA, POSTIGLIONE, OLIVEIRA, 2007, p 2), descreve que os registros servem como uma possibilidade aos governantes montar um planejamento que garanta melhor qualidade de vida à população, de acordo com o espaço que vive.

\section{APLICAÇÃO DO CADASTRO IMOBILIÁRIO NO BAIRRO MUCHILA}

Documentos históricos relacionados ao bairro ${ }^{1}$ demostram que seu surgimento ocorreu devido a chegadas de portugueses nas terras da fazenda. Já sua nomenclatura se baseia na lenda de que os portugueses trouxeram consigo mochilas, com ouro, e as enterraram nas terras da fazenda. Com o passar dos anos, o bairro ganhou destaque por ser localizado nas proximidades do Centro comercial da cidade, pois facilitava o acesso ao comércio, e às rodovias mais importantes.

As condições de infraestrutura propostas pelo poder público no Bairro Muchila foram importantes para garantir os investimentos voltados ao bairro, pois, segundo o Secretário $^{2}$, foram criados projetos de desenvolvimento e melhorias para a área, como praças, postos de saúde, etc. A análise cadastral demonstrou que a construção de empreendimentos como condomínios, grandes supermercados, um teatro, o INSS e um centro de saúde para idosos, dentre outros, gerou especulação imobiliária, atrativos e visibilidade para a área, o que aumenta seu potencial de crescimento.

Os mapas temáticos resultaram em dados atualizados do bairro e através das informações coletadas foi possível identificar as vias públicas que se desenvolveram e caracterizar as modificações de sua configuração inicial (Mapa 1). É possível identificar que há predominância de residências, intercaladas com domicílios mistos, usados para moradia e terciário. Algumas casas comerciais também começam a surgir por toda a imediação, tais como restaurantes, bares, farmácias, conveniências, mercados, templos religiosos e até escritórios de advocacia, localizados nas vias principais do bairro. Esses empreendimentos foram implantados nas proximidades das casas e condomínios e seguem por todas as imediações do bairro.

O Mapa 2 caracteriza o tipo de uso e ocupação do solo e demonstra que as localizações dos empreendimentos seguem uma organização de acordo com as principais demandas da população residente. Um exemplo são os empreendimentos localizados no entorno do INSS, onde predominam os escritórios de advocacia, além de lanchonetes e restaurantes, cujo o objetivo é atender as necessidades dos visitantes. Nas áreas internas destaca-se que o tipo de utilização maior são supermercados, templos religiosos, lanchonete e postos de saúde.

${ }^{2}$ Entrevista aplicada em 11/03/2020 com o Secretário da Fazenda (SEFAZ). Realizada por Adriana Silva 
Mapa 1: Caracterização do Uso e Ocupação do Bairro Muchila, 2020:

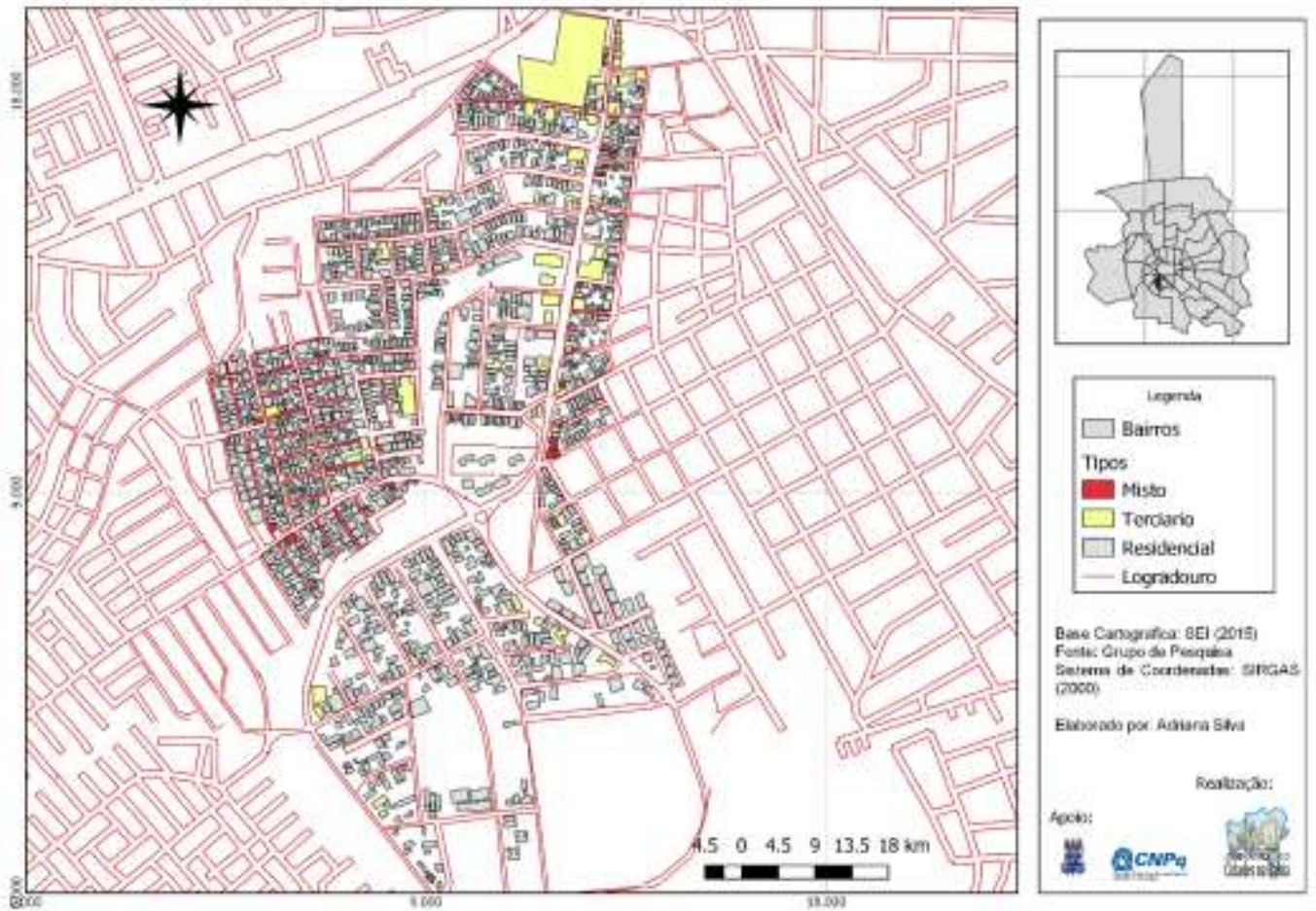

Mapa 2: Caracterização do Tipo Especifico de Uso e Ocupação do Bairro Muchila, 2020:

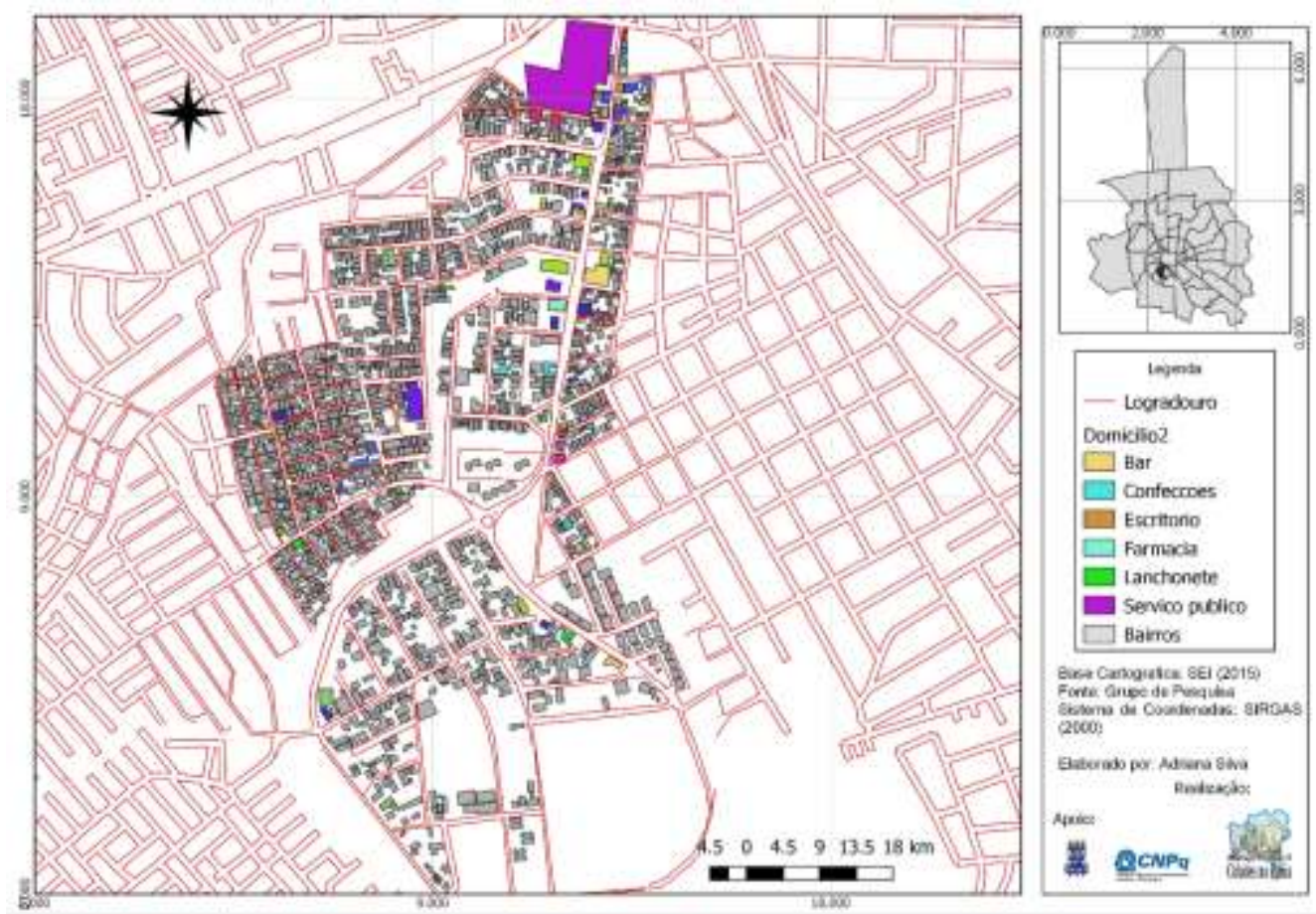

Foi possível notar a organização do bairro e que ainda há áreas sem construção ou em processo de construção. Com o mapa 3, em 3D, foi o de caracterizar os empreendimentos que existem na avenida e no seu entorno o e também de diferenciar os tipos de atividades que ocorrem na mesma.

A construção desses mapas contribui bastante para o planejamento urbano, sobretudo na cidade de Feira de Santana, já que a mesma não possui uma base de dados cadastral atual referente ao crescimento urbano da cidade. 
Mapa 3: Caracterização em 3D do Tipo de Uso e Ocupação do Bairro Muchila, 2019:

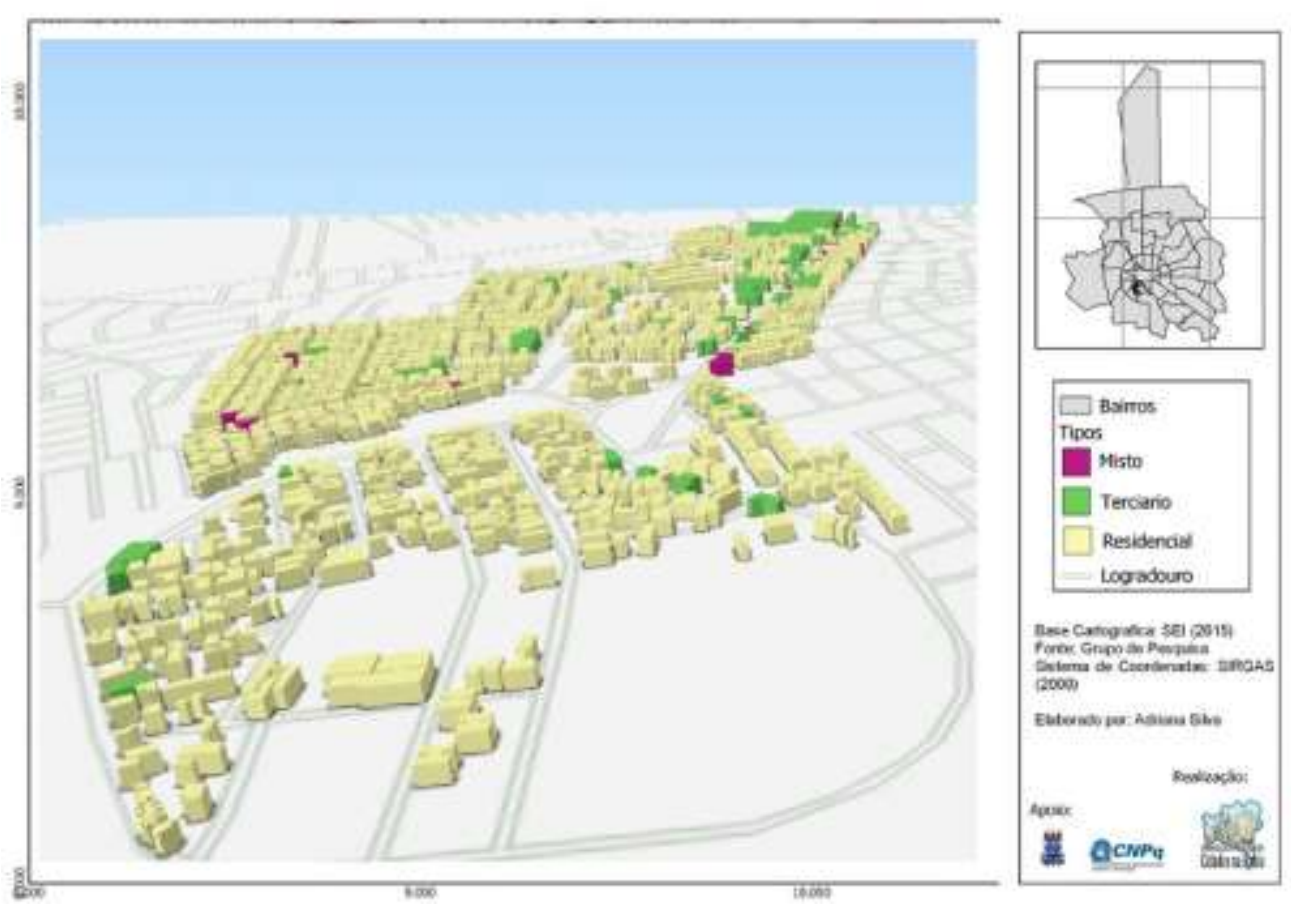

\section{CONSIDERAÇÕES FINAIS}

Ao longo da pesquisa, foi possível identificar que os agentes responsáveis pelo crescimento urbano de Feira de Santana tiveram participação na (re)configuração da dinâmica do bairro Muchila, visto que geraram investimentos nos setores econômicos, imobiliários e comerciais. Pode-se constatar que as características de localização e especulação imobiliária foram importantes para transformar o bairro em uma área de potencial econômico, pois impulsionaram investimentos, como a construção do Teatro Maestro Miro e o INSS, que trouxeram valorização para a área.

O crescimento do setor imobiliário fortaleceu a valorização fundiária, pois nos bairros e arredores foram instalados novas casas, prédios e condomínios, o que gera uma preocupação para a gestão pública, pois não se tem uma base de dados com informações atualizadas sobre o crescimento da via e as mudanças que ocorram ao longo dos anos, o que mostra a relevância da elaboração de um cadastro imobiliário.

\section{REFERÊNCIAS}

ARGENTA, A.; POSTIGLIONE, G.da S.; OLIVEIRA, F. H. de. A importância do cadastro urbano para fins de planejamento urbano - experiência em Florianópolis/Brasil e Santa Fé/Argentina. In: ENCUENTRO DE GEÓGRAFOS DE AMÉRICA LATINA, 11,. Anais [...]. Florianópolis: Centro de Ciências Humanas e da Educação - FAED, 2007. p 1-10.

CORDOVEZ, J.C.G. Geoprocessamento como Ferramenta de Gestão Urbana. In: I SIMPÓSIO REGIONAL DE GEOPROCESSAMENTO E SENSORIAMENTO REMOTO. Anais [...]. Aracaju, 2002.

SOUZA, M. L de. A teorização sobre o desenvolvimento em uma época de fadiga teórica, ou: sobre a necessidade de uma "teoria aberta" do desenvolvimento sócioespacial. Revista Território, n. v., 1996, p. 1-22 